\title{
Role of erythropoietin in methotrexate-induced nephrotoxicity in adult male albino rats
}

\author{
Ahmed Hassan Al-Rashidy ${ }^{1,2 *}{ }^{\mathbb{D}}$, Rasha Rabea Salem ${ }^{3,4}$, Amal Abdelrasool Alhosary ${ }^{5,6}$, Mohamed Hassan \\ Wahdan $^{7,8}$, Gamal Mohamed Elnemr ${ }^{9,10}$, Khalid Ebraheem Hassan ${ }^{11}$, Atif Ibrahim Ali ${ }^{12}$ \\ ${ }^{1}$ Department of Pathology, College of Medicine, Taif University, Kingdom of Saudi Arabia \\ ${ }^{2}$ Department of Pathology, Faculty of Medicine (Assiut), Al-Azhar University, Egypt \\ ${ }^{3}$ Department of Anatomy and Embryology, College of Medicine, Taif University, Kingdom of Saudi Arabia \\ ${ }^{4}$ Department of Anatomy and Embryology, Faculty of Medicine, Alexandria University, Egypt \\ ${ }^{5}$ Department of Clinical Pathology, College of Medicine (Female), Taif University, Kingdom of Saudi Arabia \\ ${ }^{6}$ Department of Clinical Pathology, Faculty of Medicine, Menoufia University, Menoufia, Egypt \\ ${ }^{7}$ Department of Anatomy and Embryology, College of Medicine, Taif University, Kingdom of Saudi Arabia \\ ${ }^{8}$ Department of Anatomy and Embryology, Faculty of Medicine, Cairo University, Egypt \\ ${ }^{9}$ Department of Internal Medicine, College of Medicine, Taif University, Kingdom of Saudi Arabia \\ ${ }^{10}$ Department of Medical and Radiological Researches, Nuclear Materials Authority, Egypt \\ ${ }^{11}$ Department of Pathology, College of Medicine, Taif University, Kingdom of Saudi Arabia \\ ${ }^{12}$ Department of Histology, Faculty of Medicine (Cairo), Al-Azhar University, Egypt
}

\section{A R T I C L E I N F O}

Article Type:

Original

\section{Article History:}

Received: 18 January 2018

Accepted: 17 April 2018

ePublished: 22 May 2018

\section{Keywords:}

Erythropoietin

Methotrexate

Nephrotoxicity

\begin{abstract}
A B S T R A C T
Introduction: Methotrexate (MTX) could provoke a renal dysfunction. However, beneficial extra-hematopoietic effect of erythropoietin might guard against MTX-induced nephrotoxicity. Objectives: Determination of renoprotective erythropoietin's role against MTX-induced nephrotoxicity through elucidating its renofunctional and renomorphological effects in adult male albino rats.

Materials and Methods: The study was performed on 60 adult male Albino rats, equally divided into three groups; group 1 (control): treated with intraperitoneal injections of normal saline at a dosage of $0.5 \mathrm{mg} / \mathrm{kg}$ BW twice weekly for 9 weeks. group 2: injected with MTX hydrate intraperitoneal twice weekly at a dosage of $0.5 \mathrm{mg} / \mathrm{kg}$ BW for 9 weeks; and group 3: intraperitoneal injected with MTX hydrate in a similar dosage and duration like group 2 concomitant with subcutaneous injection of $100 \mathrm{IU} / \mathrm{kg}$ recombinant human erythropoietin once weekly for 9 weeks. At the study end, serum urea and creatinine together with albuminuria were measured, rats were sacrificed and renal sections were prepared for histopathological examination.

Results: Significantly increased values of renal function analyzed substances with deteriorated histopathological renal changes were detected in the MTX-treated group compared to either the control or to the MTX and erythropoietin co-treated group. The later displayed statistically significant decreased levels of the substances accompanied by remarkably ameliorated microscopic renal changes. Additionally, insignificant statistical biochemical and morphological renal differences were noticed between the third and control groups.

Conclusion: This study concluded valuable and efficient defense against MTX-induced nephrotoxicity in adult male Albino rats when co-treated with erythropoietin.
\end{abstract}

Implication for health policy/practice/research/medical education:

Our study revealed that MTX had produced both renal functional and structural impairment. However, concomitant administration of erythropoietin with MTX had protected the kidneys both biochemically and histopathologically.

Please cite this paper as: Al-Rashidy AH, Salem RR, Alhosary AA, Wahdan MH, Elnemr GM, Hassan1 KH, et al. Role of erythropoietin in methotrexate-induced nephrotoxicity in adult male albino rats. J Nephropharmacol. 2018;7(2):156-163. 


\section{Introduction}

Anticancer therapy may be chased with kidney damage exemplified by disturbed tubular and/or glomerular function (1,2). Common unfavorable renal effects of childhood cancer chemotherapy include acute renal injury, tubulointerstitial disorder, capillary endothelial damage and electrolytes as well as acid-base disturbances (3). Renal disorders occurring with chemotherapeutic drugs are caused by low renal blood supply, tubular obstruction, renal parenchymal and microvascular structural damage (4-6).

One of the broadly used anticancer drugs is methotrexate (MTX) that acts as a typical anti-folate. A large dose of MTX is called high-dose MTX (HDMTX) which is given by delayed i.v. infusion in the patients with the normal renal function following an excess fluid intake and alkalinization to obtain the drug solubility in urine. Co-administration of leucovorin greatly protects against fatal MTX toxicity (7). However, MTX-induced nephrotoxicity endures even though infrequently with these protective measures. Since MTX is removed through excretion from the kidney, however, MTX-induced renal disturbed function is associated with an interrupted MTX removal resulting in continuous elevation of its plasma concentration with a subsequent obvious development of MTX-toxic manifestations predominantly myelosuppression as well as hepatic, cutaneous and mucosal inflammation (8). Moreover, a lot of drugs such as nonsteroidal anti-inflammatory, penicillin, probenecid, and sulfisoxazole when concomitantly given with MTX, they have been accompanied by enhanced nephrotoxicity due to their interference with excretion of MTX from the kidney and by challenging in the renal tubular secretion (7). Development of MTX- induced renal dysfunction is indicated by sudden elevation of serum creatinine together with a significant increase of the concentration of MTX in the plasma $(9,10)$. Furthermore, a significant hepatic dysfunction associating HDMTX therapy has not essentially been accompanied by renal failure development (7).

Erythropoietin (EPO) considered as a growth factor, is crucial in cell proliferation and neovascularization. In addition, EPO biochemically is a glycoprotein released by interstitial cells, found in a soluble form in the circulation, and promotes erythropoiesis. It largely treats anemic patients with the end-stage kidney disorder and patients with allograft kidney (11-13). Moreover, it is applied to guard renal tissue against reperfusion damage (14). EPO is recently evidenced to have several additional biological tasks that can keep several organs including the kidney in case of ischemic renal injury (IRI) despite the actual molecular pathogenesis of EPO self-protective effect remains indistinct (15). However, toll-like receptors (TLRs) are thought to be the keystone molecules in the regulation of inflammatory responses. Also, significantly increased expression of TLR4 from the renal tubular epithelial cells is confirmed and therefore, it activates the nuclear factor kappa-light-chain-enhancer of activated $\mathrm{B}$ cells $(\mathrm{NF}-\mathrm{kB})$ and helps the expression of various inflammatory factors detected in IRI (16).

One of the essential side effects of oncotherapeutic drugs is nephrotoxicity that is distinguished by a diminished glomerular filtration rate and renal blood supply $(17,18)$. The ameliorating and defensive effect of EPO against cisplatin-induced nephrotoxicity was stated in female (19) and male (20) rats as well as in other experimental animals (20-22).

\section{Objectives}

The target of the study was detection of the protective and improving role of EPO against MTX provoked toxic renal injury in male rats.

\section{Materials and Methods Animals}

Sixty adult male albino rats of body weight about 200-250 $\mathrm{g}$ were obtained from animal house, Jeddah, KSA. They were housed at the animal house at $21-22^{\circ} \mathrm{C}$ in a $12 / 12$ hours light/dark cycle, fed a standard rat chow and given free access to water.

\section{Experimental design}

The rats were housed in the animal housing facility of the laboratory of experimental surgery and surgical research, medical college, Taif University, in a controlled environment. The permission of animal use in our study was obtained from Taif University that supported this research. All conditions follow normal and standards laboratory circumstances (21) including cages and the environment with $55 \%$ relative humidity, central ventilation (15 air changes $/ \mathrm{h}$ ), a temperature of $20^{\circ} \mathrm{C} \pm 2^{\circ} \mathrm{C}$ and artificial 12-hour light-dark cycle. After two weeks of acclimatization period, the animals were equally divided into three groups (each involved 20 rats). All groups were maintained on standard chow diet for 9 weeks;

Group 1: Animals were served as control and treated with intraperitoneal injections of normal saline at a dosage of $0.5 \mathrm{mg} / \mathrm{kg}$ BW twice weekly for the total duration of 9 weeks.

Group 2: Animals were injected with MTX hydrate intraperitoneal twice weekly at a dosage of $0.5 \mathrm{mg} / \mathrm{kg} \mathrm{BW}$ for the total duration of 9 weeks.

Group 3: Animals were injected with MTX hydrate intraperitoneal twice weekly at a dosage of $0.5 \mathrm{mg} / \mathrm{kg} \mathrm{BW}$ for 9 weeks concomitant with subcutaneous injections of $100 \mathrm{IU} / \mathrm{kg}$ recombinant human EPO (rhEPO) once weekly for 9 weeks (total of 9 injections).

At the end of the experiment, blood and urinary 
samples were collected to measure concentrations of serum (S) creatinine and serum urea as well as urinary microalbuminuria to assess renal function. Blood and urine samples were measured as follows:

- Blood urea level $(\mathrm{mg} / \mathrm{dL})$ by the enzymatic method (modified Berthelot reaction) ( $\mathrm{dp}$ international; Tuscaloosa, USA).

- Serum creatinine level $(\mathrm{mg} / \mathrm{dL})$ by a colorimetric kinetic method (Bio-diagnostic; Paterson, New Jersey, United States).

- Albumin in urine $(\mathrm{mg} / \mathrm{dL})$ by Folin-Lowry Colorimetric Method (Bio-diagnostic; Paterson, New Jersey, United States).

Lastly, all rats belonging to the three groups were sacrificed by the overdose of anesthesia. From each rat, autopsy renal specimens were excised and washed several times with normal saline, immediately fixed in $10 \%$ neutral buffered formalin. After proper fixation, the specimens were washed in tap water, dehydrated in serial ethyl alcohol, cleared in xylol, embedded and cast in paraffin. Thin paraffin sections (3-4 microns) were prepared, put on charged glass slides and stained with hematoxylin and eosin for general morphological examination and detection of the histopathological changes, Mallory's trichrome for detection of collagen fibers and Periodic Acid Schiff (PAS) with diastase for detection of glycogen content of renal tubular lining cells and basement membranes of the renal parenchymal structures (23).

\section{Ethical issues}

The experimental protocol was approved in advanced by Taif University Ethics Committee (Code \# 21974). The research followed the tenets of the Declaration of Helsinki. The protocol of this study is also designed in accordance with the ethical principles of the International Committees for the Protection of Animal Rights Laboratory.

\section{Statistical analysis}

Data were collected and analyzed using SPSS software package version 17. Quantitative data were analyzed using F-test (ANOVA) to compare the different groups. Pearson's coefficient was used to estimate the correlation between different parameters. Additionally, $P$ values derived from least significant difference (LSD) test $\leq 0.05$ was assumed to be significant.

\section{Results}

Table 1 and its chart (Figure 1) showed insignificant statistical differences in the mean values of all renal function biochemically analyzed substances in the MTXEPO-managed group (G3) when compared to the control group (G1) $(P>0.05)$. However, the MTX-treated group (G2) revealed marked nephrotoxicity indicated by a highly statistically significant increase in the mean values of serum urea and creatinine as well as of urine albumin level $(P<0.05)$ when matched to the control group. On the contrary, the third group displayed a highly statistical significant decrease in the mean values of serum urea and creatinine as well as of urine albumin level $(P<0.05)$ when challenged with the second group.

Microscopically, the control renal sections revealed normal parenchymal tissue including renal glomeruli and renal tubules that possessed regular lumen and lined by cubical epithelial cells (Figure 2-G1). However, in group 2, MTX caused degeneration of renal tubules and disruption of their basement membranes. The majority of renal tubules showed a cystic luminal dilatation and flattened epithelial cell lining. Moreover, the glomeruli were degenerated (Figure 2-G2). In addition, markedly reduced toxic renal structural changes were noticed in the group 3 renal sections administrated EPO concomitant with MTX. Improved histopathological changes detected in group 3 were evidenced by morphological return nearly back to the normal appearance of the control group except for mildly dilated few renal tubules (Figure 2-G3).

In addition, periodic acid-Schiff (PAS) with diastase stain displayed a strong eosinophilic cytoplasmic reaction within the renal tubular lining cells as well as integrity of tubular basement membranes in both control (Figure 3-G1) and third (Figure 3-G3) groups regarding apparently disrupted tubular basement membranes in the group 2 despite a morphologically unremarkable change in the glycogen content within its lining cells (Figure 3-G2).

Furthermore, Mallory's trichrome stain showed a normally distributed collagen in the renal parenchymal tissue together with intact renal tubular and glomerular basement membranes as well as an intact glomerular Bowman's capsule in the control group (Figure 4-G1).

Table 1. Results of biochemically analyzed substances in all groups

\begin{tabular}{|c|c|c|c|c|c|c|}
\hline \multirow[b]{2}{*}{ Analyzed substances } & \multicolumn{3}{|l|}{ Groups } & \multirow{2}{*}{$\begin{array}{l}P \text { value (G1- } \\
\text { G2) }\end{array}$} & \multirow[b]{2}{*}{$\begin{array}{l}P \text { value } \\
\text { (G1-G3) }\end{array}$} & \multirow{2}{*}{$\begin{array}{l}P \text { value } \\
\text { (G2-G3) }\end{array}$} \\
\hline & $\begin{array}{l}\text { Group } 1 \\
\text { (Mean } \pm \text { SD) }\end{array}$ & $\begin{array}{l}\text { Group } 2 \\
\text { (Mean } \pm \text { SD) }\end{array}$ & $\begin{array}{l}\text { Group } 3 \\
\text { (Mean } \pm \text { SD) }\end{array}$ & & & \\
\hline Serum urea (mg/dL) & $40.27 \pm 5.149$ & $65.89 \pm 8.65$ & $41.05 \pm 1.78$ & 0.0001 & 0.059 & 0.0001 \\
\hline Serum creatinine $(\mathrm{mg} / \mathrm{dL})$ & $1.24 \pm 0.137$ & $4.57 \pm 0.524$ & $1.34 \pm 0.259$ & 0.0001 & 0.074 & 0.0001 \\
\hline Urine albumin (mg/dL) & $25.39 \pm 6.081$ & $42.35 \pm 9.226$ & $28.46 \pm 5.042$ & 0.0001 & 0.059 & 0.0001 \\
\hline
\end{tabular}

$P$ values were derived from LSD test. 


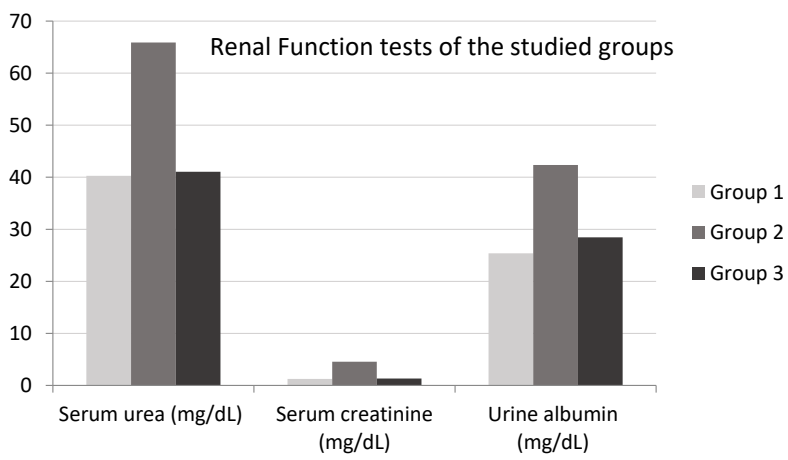

Figure 1. A chart representing renal function tests in the three studied groups. The histogram showed significant elevation of serum urea and creatinine as well as urine albumin in the MTXtreated group (G2) when compared to the control group (G1) or the MTX - EPO-managed group (G3). In contrast, group 3 revealed insignificant mean values of all biochemical analyzed substances when compared to the control group 1.

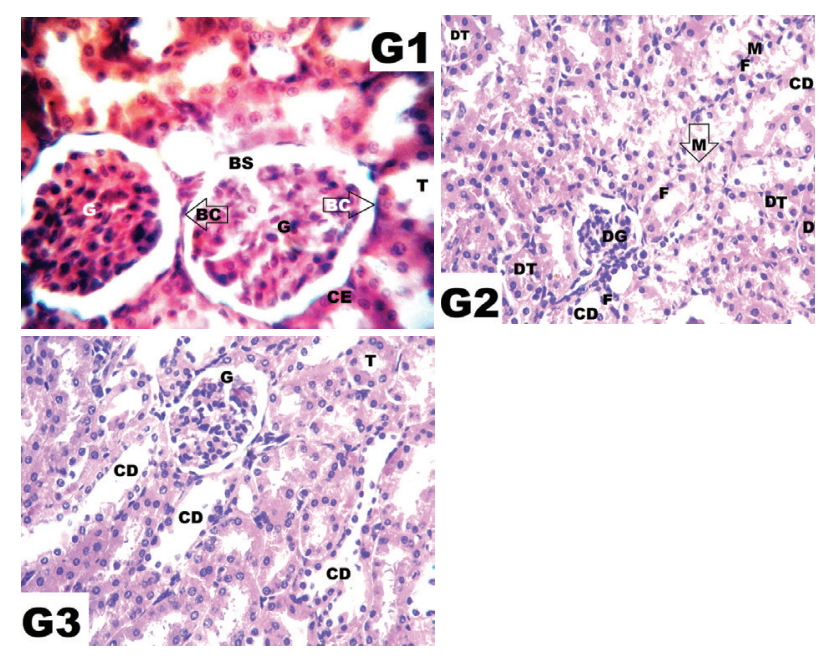

Figure 2. A photomicrograph of a control rat kidney section (G1) displayed normal glomeruli (G) with its Bowman's capsule (BC inside arrows) and Bowman's space (BS) and renal tubules (T) that are lined by cubical epithelial cells (CE) (H\&E×500). However, a photomicrograph of group 2 rat renal section (G2) displayed degenerated renal tubules (DT) with disruption of their basement membrane (M). Most of the renal tubules show cystic dilatation of their lumen (CD) and their lining epithelial cells were flat $(\mathbf{F})$. Degenerated glomeruli (DG) were also observed. In contrast to G2, the photomicrograph of group 3 rat renal section (G3) displayed greatly ameliorated histological features that more or less similar and nearly returned to normal as in the control group section, however, few renal tubules were still dilated (CD) (H\&E ×400).

However, relatively increased collagen fibers both in the glomeruli and around the renal tubules together with disrupted both glomerular and tubular basement membranes were detected in the group 2 (Figure 4-G2). In group 3 (Figure 4-G3), the structural changes observed in the group 2 were ameliorated and came nearly back to the normal appearance detected in the control group.
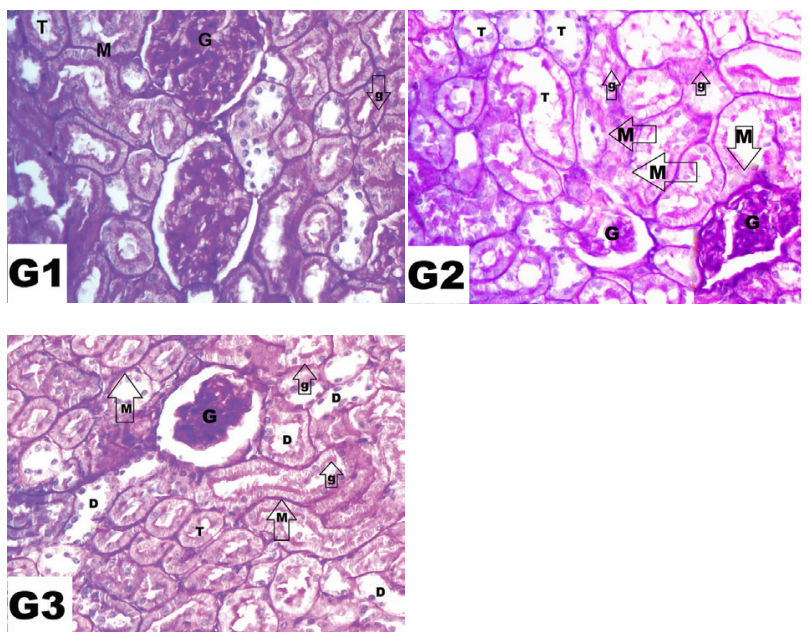

Figure 3. A photomicrograph of control rat renal section (G1) displayed PAS-positive cytoplasmic granules (g inside arrows) within the tubular lining cells $(\mathbf{T})$. Moreover, a group 2 rat renal section (G2) photomicrograph displayed disrupted tubular basement membranes (M inside arrows) despite unremarkably changed glycogen ( $\mathbf{g}$ inside arrows) content observed within its lining cells. Also, the $\mathrm{G} 2$ photomicrograph showed degenerated glomeruli (G) and tubules (T). In contrast to $\mathrm{G} 2$, a photomicrograph of group 3 rat renal section (G3) displayed a greatly improved renal glomeruli (G) and tubules (T) that nearly resembled the normal control appearance regarding the cellular content of glycogen ( $g$ inside arrows) and basement membranes ( $M$ inside arrows) but renal tubules were still dilated (D) (PAS with diastase stain $\times 400$ ).

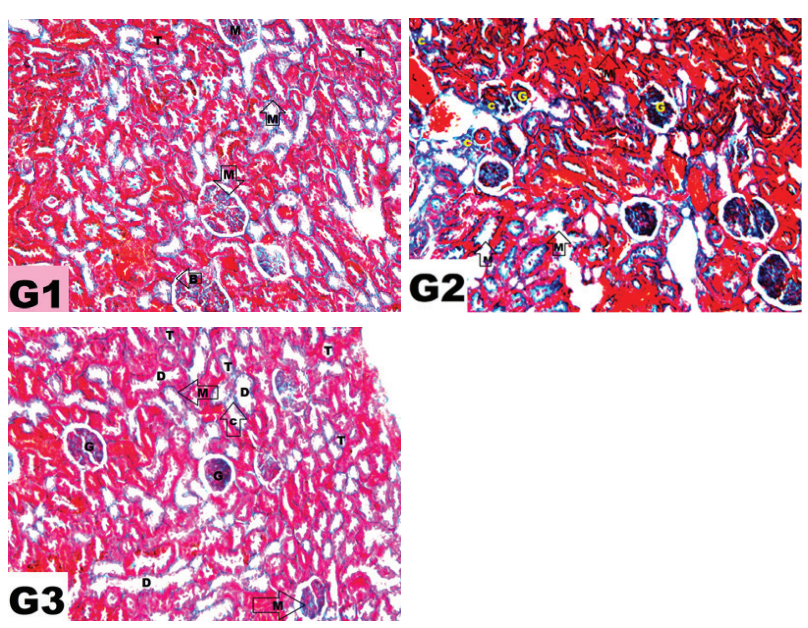

Figure 4. A photomicrograph of a control rat renal section (G1) showed a normally distributed blue collagen fibers in the renal parenchymal tissue with intact blue basement membranes (M inside arrows) of both renal tubules ( $\mathbf{T}$ ) and glomeruli (G) and intact blue glomerular Bowman's capsule (B inside arrow). However, a photomicrograph of group 2 rat renal section (G2) displayed relatively increased peritubular and glomerular collagen fibers (c) as well as disrupted both glomerular (G) and tubular basement membranes (M inside arrows). In group 3 rat renal section (G3), the structural changes observed in group 2, including increased collagen fibers in the glomeruli $(\mathbf{G})$ and around the renal tubules (T) as well as the disrupted glomerular and tubular basement membranes ( $\mathbf{M}$ inside arrows), were came back to the normal appearance characterizing the control group despite constantly dilated $(D)$ renal tubules (Mallory's trichrome $\times 150$ ). 


\section{Discussion}

The main indicators of renal function are creatinine and blood urea nitrogen (BUN) that are catabolic protein products chiefly metabolized by the kidney. When the renal function is disturbed beyond its compensatory capacity, the BUN and serum creatinine levels are apparently increased. As mentioned before, the administration of HDMTX is essential in oncotherapy of several childhood and adulthood cancers and can be safely used with leucovorin in normal renal function patients following alkalinization and hydration tools. However, renal dysfunction with HDMTX administration even with these protective tools is seen with chemotherapy of patients having osteosarcoma (7). Our study aimed at prevention and amelioration of MTX-induced nephrotoxicity to avoid potentially life-threatening MTX-associated toxicities stated by Widemann and Adamson particularly bone marrow suppression and mucocutaneous as well as hepatic inflammation (7). We displayed variable renal parenchymal structural changes associated with significantly increased serum urea and creatinine together with elevated urinary albumin levels in the treated group with MTX. The structural changes included degeneration of renal tubules and glomeruli, disruption of their basement membranes and relatively increased collagen fibers both peritubular and in the glomeruli. In addition, the majority of renal tubules showed a cystically dilated lumen with flattening of their lining epithelial cells irrespective of unremarkably changed glycogen content observed within its lining cells. These findings coincided with those detected by Sharbaf et al who stated that the amount of oncotherapeutic drug in the tubular cells of the kidney exceeds several times its amount in the extracellular compartment and its major uptake occurs in the proximal renal tubules (24). In addition, Liao et al found a significant rise in both blood BUN and creatinine levels in the ischemic rat kidney at 4, 12 and 24 hours following renal reperfusion and they indicated a damage of the renal parenchymal tissue after reperfusion of ischemia so that the renal excretory capacity of urea nitrogen and creatinine was largely diminished (16).

Smeland et al together with Messmann and Allegra stated that MTX-induced renal nephrotoxicity occurs due to either renal tubular precipitation of the drug or its metabolites or direct renal tubular damaging effect of the drug $(25,26)$. Furthermore, Rjiba-Touati et al documented that drug-induced nephrotoxicity is due to accumulation of toxic free radicals associated with renal tubular cellular damage by lipid peroxidation process (27). Additionally, Widemann and Adamson mentioned that the majority of MTX is removed from the human body via the urine and the drug and its metabolites are weakly soluble in acidic urine, therefore, parenteral administration of HDMTX in a short duration is accompanied by elevated drug concentration both in blood and urine with subsequent higher risk of development of the renal dysfunction (7).

Watowich suggested that EPO has a paracrine role and detected EPO receptor which is encoded by messenger RNA in many tissues involving the renal one (28). In our study, EPO co-administrated with MTX markedly reduced the abnormal toxic renal structural and biochemical changes noticed in the group 3. This group revealed improvement of histopathological changes involving the extent of collagen fibers in the glomeruli and around the renal tubules that nearly returned back to the normal appearance of the control one apart from mildly dilated renal tubules. Additionally, the biochemical renal analyzed group 3 findings were significantly declined to approximate those of control normal one (28). Our results simulated those of Liao et al who found a decrease of BUN and serum creatinine levels in EPO-treated group of rats within 4, 12 and 24 hours following renal reperfusion than their values in rat group having renal ischemic injury and therefore, they confirmed the defensive EPO effect on the renal ischemia. In addition, they verified that the pathologic renal ischemic changes have been attributed to renal cellular apoptosis, endothelial injury of the renal vessels, oxidative stress of the renal tissue and the inflammatory reaction within the kidney (16). Our group 3 results were identical to those of Zafirov et al who distinguished a decreased proteinuria in the group of rats treated with EPO which exerted its renoprotective action due to an induction of proliferative and regenerative capacities of the tubular cells and consequently avoid the renal damaging effect of cisplatin drug (29). Additionally, Yang et al stated that EPO may act as an anti-apoptotic factor through suppression of both apoptosis-inducing factor and apoptosis protease-activating factor-1 (30). Hassan et al mentioned that EPO after binding to its receptor can enhance various genes transcription, thus, acting as a survival agent and they, as well, discovered an ameliorated kidney function in the group of diabetic rats given EPO (31). Similarly, Toba et al established the renoprotective EPO action through the improvement of proteinuria, impaired renal function and renal fibrosis of the diabetic rats after chronic management with a low EPO dosage (32). Identically, Pallet et al (33) stated that the anti-apoptotic function of EPO is evidenced by the production of anti-apoptotic proteins of the Bcl-2 family like Bcl-2 and Bcl-x (L) which interfered with tubular epithelial lining cell death and consequently resulted in an enhancement of tubular epithelial cell regeneration and elicited the retrieval of kidney function as declared by Sharples and Yaqoob (34). Furthermore, Vesey et al suggested that EPO could exert its anti-apoptotic property in both ischemic renal and hypoxic circumstances (14).

The renoprotective effect of EPO is verified by Baek et al, Brøchner et al, Khalid et al who detected an excessive 
release of interleukins and tumor necrosis factor in case of IRI both in local renal tissue and generalized in the blood and interpreted that EPO diminished the contents of these inflammatory mediators in both locations through extrahematopoietic inhibitory action of EPO on the release of these mediators (35-37). Additionally, as mentioned before, Lee et al (38); O'Neill et al (39), Chen et al (40), Ozbilgin et al (41), and Liao et al (16) confirmed that ischemic reperfusion of the kidney was associated with local (in the renal tissue) overexpressed TLR4 receptor which triggers $\mathrm{NK}-\mathrm{kB}$ and local overexpressed NF-kB protein receptor that enhances the interleukins and tumor necrosis factor transcriptions and they accounted that the expression of these inflammatory mediators was suppressed with EPO management indicating that EPO could minimize the synthesis of these mediators through inhibition of the TLR4/NFkB pathway.

Besides, our third group results were in accordance to those of Rjiba-Touati et al who mentioned that the administration of EPO prior to, coincident with or subsequent to cisplatin treatment had improved cisplatin-induced nephrotoxicity via the reduction of an impaired renal function which was induced by this chemotherapeutic drug. They pointed this improvement to the EPO antioxidant action that could eradicate oxygen free radicals responsible for the oxidative stress of renal tissue (27).

Kumral et al mentioned that EPO, besides its antiinflammatory character, activated the antioxidant enzymes and thus inhibited the production of nitric oxide and diminished lipid peroxidation (42).

Zhang et al affirmed that transcriptional hypoxiainducible factor-1a is responsible for adaptation of the cells to a decreased oxygen pressure. It controls the genes correlated to neovascularization, cell proliferation and cell survival in addition to genes related to iron and glucose metabolism (43). Moreover, Park et al discovered that EPO has a protective role to diminish the renal fibrosis in mice via inhibition of transforming growth factor beta (44). Finally, Schiffer et al demonstrated that EPO prevents the development of glomerular fibrosis through a direct ameliorating effect on its podocyte damage (45).

\section{Conclusion}

In conclusion, our study confirmed the renoprotective and ameliorating roles of EPO on both structure and function of the male Albino rat nephrotoxicity induced by MTX drug. Therefore, supplementation of EPO is essential concomitant with MTX chemotherapy.

\section{Recommendations}

First, future studies on a wider scale have to be carried out in renal toxicity induced by various chemotherapeutic drugs on various animal models to confirm the protective and therapeutic effects of EPO. Second, EPO, that is greatly safe, cheap and available drug, can be attempted on human MTX-induced nephrotoxicity.

\section{Acknowledgments}

At first, we would like to express our deep thanks and gratitude to Taif University, KSA research Deanship for their financial support of our project to its end. We would like also to present our thankfulness and gratitude to $\mathrm{Mr}$. Gamal Abdullah (Microscopic Technician) for his help and follow up of this research. Our thankfulness and gratitude are extended also to Faisal Faheed Alsobaiti (Medical Resident in Department of Internal Medicine, King Faisal Hospital) and to Wissam Khalil Haider Almanadili, Ammar Saud Jamaan Altowairqi and Abdullah Ayesh Abdullah Altalhi (Undergraduate students, College of Medicine, Taif University) for their help in the final stage of this work.

\section{Authors' contribution}

AHAR suggested and implemented the title of the research. Moreover, AHAR together with $\mathrm{KEH}$ and AIA were responsible for histopathological renal tissue section preparation, staining and diagnosis as well as evaluation of the renal normal and abnormal structural findings. RRS and MHW were responsible for follow up the groups of rats, administrated the drugs for the groups and sacrificed the animals and excised their kidneys. AAA and GME were responsible for the biochemical analysis and evaluation of the renal function in all groups. Finally, all authors participated in the editing of the original research.

\section{Conflicts of interest}

The authors declare no conflict of interest.

\section{Ethical considerations}

Ethical issues (including plagiarism, data fabrication, double publication) have been completely observed by the authors.

\section{Funding/Support}

According to the rules of research system of Taif University, Our University funded the purchase of the required animals, materials, stains and biochemical kits.

\section{References}

1. Denker B, Robles-Osorio ML, Sabath E. Recent advances in diagnosis and treatment of acute kidney injury in patients with cancer. Eur J Intern Med. 2011;22:348-54. doi: 10.1016/j.ejim.2011.02.002.

2. Lameire N, Van Biesen W, Vanholder R. Electrolyte disturbances and acute kidney injury in patients with cancer. Semin Nephrol. 2010;30:534-47. doi: 10.1016/j. semnephrol.2010.09.002.

3. Salahudeen AK, Doshi SM, Pawar T, Nowshad G, Lahoti 
A, Shah P. Incidence rate, clinical correlates, and outcomes of AKI in patients admitted to a comprehensive cancer center. Clin J Am Soc Nephrol. 2013;8:347-54. doi: 10.2215/ CJN.03530412.

4. Lameire N, Kruse V, Rottey S. Nephrotoxicity of anticancer drugs - An underestimated problem? Acta Clin Belg. 2011;66:337-45. doi: 10.2143/ACB.66.5.2062585.

5. Salahudeen AK, Bonventre JV. Onconephrology: The latest frontier in the war against kidney disease. J Am Soc Nephrol. 2013;24:26-30. doi: 10.1681/ASN.2012070690.

6. Perazella MA. Onconephrology: Renal toxicities of chemotherapeutic agents. Clin J Am Soc Nephrol. 2012;7:1713-21. doi: 10.2215/CJN.02780312.

7. Widemann BC, Adamson PC. Understanding and managing methotrexate nephrotoxicity. Oncologist. 2006;11:694-703. doi: 10.1634/theoncologist.11-6-694.

8. Stark AN, Jackson G, Carey PJ, Arfeen S, Proctor SJ. Severe renal toxicity due to intermediate-dose methotrexate. Cancer Chemother Pharmacol. 1989;24:2435.

9. Lawrenz-Wolf B, Wolfrom C, Frickel C, Fengler R, Wehinger $\mathrm{H}$, Henze G. Severe renal impairment of methotrexate elimination after high dose therapy. Klin Padiatr. 1994;206:319-26. doi: 10.1055/s-2008-1046623.

10. Widemann BC, Balis FM, Murphy RF, Sorensen JM, Montello MJ, O'Brien $M$, et al. Carboxypeptidase- $G_{2}$, thymidine, and leucovorin rescue in cancer patients with methotrexate-induced renal dysfunction. J Clin Oncol. 1997;15:2125-34.

11. Moore E, Bellomo R. Erythropoietin (EPO) in acute kidney injury. Ann Intensive Care. 2011;1:3. doi: 10.1186/21105820-1-3.

12. Yasari F, Nafar M, Alipour Abdei B, Ahmadpoor P, PourReza-Gholi F, Samadian F, et al. Effect of erythropoietin on kidney allograft survival: early use after transplantation. Iran J Kidney Dis. 2012;6:44-8.

13. Nemati E, Abbaszadeh S. Effect of erythropoietin on kidney allograft survival: early use after transplantation. Iran J Kidney Dis. 2012;6:227.

14. Vesey DA, Cheung C, Pat B, Endre Z, Gobe G, Johnson DW. Erythropoietin protects against ischemic acute renal injury. Nephrol Dial Transplant. 2004;19:348-55.

15. Zou YR, Zhang J, Wang J, Peng L, Li GS, Wang L. Erythropoietin receptor activation protects the kidney from ischemia/reperfusion-induced apoptosis by activating ERK/p53 signal pathway. Transplant Proc. 2016;48:217-21. doi: $\quad$ 10.1016/j.transproceed.2016.01.009.

16. Liao JG, Li MY, Wang XH, Xie Q. The protective effect of erythropoietin pretreatment on ischemic acute renal failure in rats. J Acute Dis. 2016;5:408-12.

17. Launay-Vacher V, Rey JB, Isnard-Bagnis C, Deray G, Daouphars M. Prevention of cisplatin nephrotoxicity: state of the art and recommendations from the European Society of Clinical Pharmacy Special Interest Group on Cancer Care. Cancer Chemother Pharmacol. 2008;61:903-9. doi: 10.1007/s00280-008-0711-0.

18. Ravindra P, Bhiwgade DA, Kulkarni S, Rataboli PV, Dhume CY. Cisplatin-induced histological changes in renal tissue of rat. J Cell Animal Biol. 2010;4:108-11.

19. Yalcin S, Müftüoğlu S, Cetin E, Sarer B, Yildirim BA, Zeybek
D, et al. Protection against cisplatin-induced nephrotoxicity by recombinant human erythropoietin. Med Oncol. 2003;20:169-74. doi: 10.1385/MO:20:2:169.

20. Lee DW, Kwak IS, Lee SB, Song SH, Seong EY, Yang BY, et al. Post-treatment effects of erythropoietin and nordihydroguaiaretic acid on recovery from cisplatininduced acute renal failure in the rat. J Korean Med Sci. 2009;24:S170-5. doi: 10.3346/jkms.2009.24.S1.S170.

21. Rjiba-Touati K, Ayed-Boussema I, Bouaziz C, Belarbia A, Azzabi A, Achour A, et al. Protective effect of erythropoietin against cisplatin-induced nephrotoxicity in rats: antigenotoxic and antiapoptotic effect. Drug Chem Toxicol. 2012;35(1):89-95. doi: 10.3109/01480545.2011.589440.

22. Mohamed HE, El-Swefy SE, Mohamed RH, Ghanim AM. Effect of erythropoietin therapy on the progression of cisplatin-induced renal injury in rats. Exp Toxicol Pathol. 2013;65:197-203. doi: 10.1016/j.etp.2011.08.006.

23. Sinha R, D'Souza D. Liver cell damage caused due to sodium benzoate toxicity in mice. Int J Biotechnol Biochem. 2010;6:549-54.

24. Sharbaf FG, Farhangi H, Assadi F. Prevention of chemotherapy-induced nephrotoxicity in children with cancer. Int J Prev Med. 2017;8:76. doi: 10.4103/ijpvm. IJPVM_40_17.

25. Smeland E, Fuskevåg OM, Nymann K, Svendesn JS, Olsen R, Lindal, et al. High-dose 7-hydroxymethotrexate: acute toxicity and lethality in a rat model. Cancer Chemother Pharmacol. 1996;37:415-22.

26. Messmann R, Allegra C. Antifolates. In Chabner B, Longo D, eds. Cancer Chemotherapy and Biotherapy. Philadelphia: Lippincott Williams \& Wilkins; 2001. p. 139-84.

27. Rjiba-Touati K, Boussema IA, Belarbia A, Achour A, Bacha H. Protective effect of recombinant human erythropoietin against cisplatin-induced oxidative stress and nephrotoxicity in rat kidney. Int J Toxicol. 2011;30(5):5107. doi: 10.1177/1091581810411931.

28. Watowich SS. The erythropoietin receptor: molecular structure and hematopoietic signaling pathways. J Investig Med.2011;59:1067-72. doi: 10.2310/JIM.0b013e31820fb28c.

29. Zafirov D, Petrusevska G, Sikole A, Trojacanec J, Labacevski N, Kostova E, et al. Erythropoietin reduces cumulative nephrotoxicity from cisplatin and enhances renal tubular cell proliferation. Prilozi. 2008;29:167-83.

30. Yang CW, Li C, Jung JY, Shin SJ, Choi BS, Lim SW, et al. Preconditioning with erythropoietin protects against subsequent ischemia-reperfusion injury in rat kidney. FASEB J. 2003;17:1754-5.

31. Hassan AED, Shaat EA, Deif MM, El Azhary NM, Omar EM. Effect of erythropoietin hormone supplementation on renal functions and the level of hypoxia-inducible factor1a in rat kidneys with experimentally induced diabetic nephropathy. Alexandria J Med. 2014;50:69-75.

32. Toba H, Sawai N, Morishita M, Murata S, Yoshida M, Nakashima K, et al. Chronic treatment with recombinant human erythropoietin exerts renoprotective effects beyond hematopoiesis in streptozotocin-induced diabetic rat. Eur J Pharmacol. 2009;612:106-14. doi: 10.1016/j. ejphar.2009.03.065.

33. Pallet N, Bouvier N, Legendre C, Beaune P, Thervet E, Choukroun G, et al. Antiapoptotic properties of 
recombinant human erythropoietin protects against tubular cyclosporine toxicity. Pharmacol Res. 2010;6:71-5.

34. Sharples EJ, Yaqoob MM. Erythropoietin in experimental acute renal failure. Nephron Exp Nephrol. 2006;104:e83-8.

35. Baek WY, Park SY, Kim YH, Lee MA, Kwon TH, Park KM, et al. Persistent low level of osterix accelerates interleukin-6 production and impairs regeneration after tissue injury. PLoS One. 2013;8:e69859. doi: 10.1371/journal. pone.0069859.

36. Brøchner AC, Dagnaes-Hansen F, Højberg-Holm J, Toft P. The inflammatory response in blood and in remote organs following acute kidney injury. APMIS. 2014;122:399-404.

37. Khalid U, Jenkins RH, Pino-Chavez G, Bowen T, Fraser DJ, Chavez R. A localized ischemic preconditioning regimen increases tumor necrosis factor a expression in a rat model of kidney ischemia-reperfusion injury. Exp Clin Transplant. 2015;13:535-42.

38. Lee JW, Kim SC, Ko YS, Lee HY, Cho E, Kim MG, et al. Renoprotective effect of paricalcitol via a modulation of the TLR4- NF-kB pathway in ischemia/reperfusion-induced acute kidney injury. Biochem Biophys Res Commun. 2014;444:121-7. doi: 10.1016/j.bbrc.2014.01.005.

39. O’Neill S, Humphries D, Tse G, Marson LP, Dhaliwal K, Hughes J, et al. Heat shock protein 90 inhibition abrogates TLR4-mediated NF-kB activity and reduces renal ischemiareperfusion injury. Sci Rep. 2015;5:12958. doi: 10.1038/ srep12958.

40. Chen H, Xing B, Wang L, Weng X, Chen Z, Liu X. Toll-like receptor 4 is involved in renoprotective effect of ischemic postconditioning after renal ischemia/reperfusion injury in rats. Urology. 2015;85:483.e1-7.

41. Ozbilgin S, Ozkardesler S, Akan M, Boztas N, Ozbilgin M, Ergur BU, et al. Renal ischemia/reperfusion injury in diabetic rats: the role of local ischemic preconditioning. Biomed Res Int. 2016;2016:8580475. doi: 10.1155/2016/8580475.

42. Kumral A, Baskin H, Gokmen N, Yilmaz O, Genc K, Genc $\mathrm{S}$, et al. Selective inhibition of nitric oxide in hypoxicischemic brain model in newborn rats: is it an explanation for the protective role of erythropoietin? Biol Neonate. 2004;85:51-4.

43. Zhang Z, Yan J, Chang Y, ShiDu Yan S, Shi H. Hypoxiainducible factor-1 as a target for neurodegenerative diseases. Curr Med Chem. 2011;18:4335-43.

44. Park SH, Choi MJ, Song IK, Choi SY, Nam JO, Kim CD, et al. Erythropoietin decreases renal fibrosis in mice with ureteral obstruction: role of inhibiting TGF-beta induced epithelial-to-mesenchymal transition. J Am Soc Nephrol. 2007;18(5):1497-507.

45. Schiffer M, Park JK, Tossidou I, Bartels J, Shushakova N, Menne J, et al. Erythropoietin prevents diabetes-induced podocyte damage. Kidney Blood Press Res. 2008;31:411-5.

Copyright $\odot 2018$ The Author(s); Published by Society of Diabetic Nephropathy Prevention. This is an open-access article distributed under the terms of the Creative Commons Attribution License (http://creativecommons.org/licenses/by/4.0), which permits unrestricted use, distribution, and reproduction in any medium, provided the original work is properly cited. 